Reviews

hunters, they often misconstrue the hunters' thinking and way of life. Dahl has much to offer on this score, emphasizing that Inuit hunting is part of the modern way of life, embedded in a larger context, the Saqqaq community, Greenland, and the Danish state. Animal rights activists share the hunters' respect for animals and their concern with environmental problems, but in many other respects the two groups are likely to disagree. Trapped in objectivist Western discourse on science and the Other, animal rights activists make a fundamental distinction between "them" (indigenous hunters) and "us" (Euro-Americans), between nature and society, and between animals and humans.

This contrasts sharply with the ways in which hunters themselves often represent their relations with society and the animate world. Thus, Inuit tend to think of themselves as being in communion with nature, animals, and fellow humans. In their view, there is no fundamental distinction between nature and society, animals are regarded as social persons, and to kill them is a sign of responsibility and not a criminal act, at least as long as certain technical and ritual conditions are met. The environmentalist view may express charitable and humanitarian motives. However, it is not an objective account of the real world but an ethnocentric statement grounded in the historical realities of particular groups of Euro-Americans.

Overall, this is quite a useful book, covering a range of ethnographic issues in plain language devoid of unnecessary jargon. Not only will it be useful in courses on hunter-gatherer society, Inuit culture, and colonial and post-colonial history, it should be valuable as well for specialists in economic and ecological anthropology. As to the weaknesses and omissions of Dahl's account, I would have liked to see more on ethnographic comparison, Inuit conceptions of human-animal interaction, gender relations, and activities performed by Saqqaq women. Also, given the emphasis on "tradition" in both Inuit and observers' accounts, a more thorough discussion of "traditional knowledge," an issue only briefly addressed (p. 228-9), should have been provided. Moreover, while Dahl provides perceptive observations of the hunting mode of production, some reference to recent critical engagements with Sahlins's thesis of the "original affluent society" would have been in order.

\title{
Where We Live, Work and Play: The Environmental Justice Movement and the Struggle for a New Environmentalism, by Patrick Novotny. London: Praeger (2000), 115 pp.
}

\section{Reviewed by Diane-Michele Prindeville, Department of Government, New Mexico State University.}

This book speaks to several different audiences in a variety of disciplines including political science, sociology, environmental studies, and communication. It introduces the reader to the diverse issues driving the work of the environmental justice movement and its grassroots supporters. Novotny recounts the history of the movement in the US, describing its goals, leaders, and proponents, while relating in detail the struggles of some of the original environmental justice organizations. The book is accessible to a general readership while still being appropriate for use by specialists and seasoned scholars interested in theory building. For example, Novotny employs "framing" as a model for explaining the success of the movement in mobilizing working-class people and communities of color. He presents this concept in terms accessible to a variety of audiences, and, as the following passage indicates, his writing style is suitable for academics while being rich and clear.

Framing is the way that the leaders in a movement assign meaning to and interpret problems in such a way as to mobilize participants. Framing is.... dynamic process by which a movement and its struggle for social change is connected with a larger set of cultural values, beliefs, and practices. ...[I]t encompasses the culture and even the language that is used in a movement. (Novotny, 2000: xviii)

The author uses the theoretical perspective of framing to explain the successful politicization of the environment, as well as the mobilization of diverse groups of supporters by movement leaders. He makes his argument by presenting the reader with case studies of four groups active in the environmental justice movement: the Gulf Coast Tenants Organization, the Labor/Community Strategy Center, the Oil, Chemical and Atomic Workers Local 4-620 all in Louisiana, and the SouthWest Organizing Project in New Mexico. Novotny effectively 
Reviews

illustrates how, in each case, the leadership of these environmental justice organizations has strategically reconceptualized local notions of "environment" in terms that directly link the community's current political struggle for economic and racial equity with that of the historic civil rights movement. Group leaders broaden narrow definitions of the environment to incorporate issues such as neighborhood housing conditions, workplace safety, community health, and access to public services. In contrast to the larger, national environmental organizations, this grassroots movement defines the environment not as a pristine and distant wilderness but as the local urban neighborhood "where we live, work, and play." As Novotny points out, "the environment... is a cultural formation, an expression of social relations." (2000: 86). Furthermore, "Nature and ideology are inextricably bound; as such, the idea of exactly what and where nature is located is fraught with ideology" (2000: 88).

While the book appeals to academics, it is potentially useful to activists who wish to learn from the organizations whose experiences are recounted here in the form of case studies. Through these case studies, Novotny describes various strategies, some more successful than others, for mobilizing community members, building coalitions, organizing protests, working the media, and influencing policy outcomes. His concluding chapter is both fresh and sharp. Rather than simply summarizing the contents of the book here, the author ends with a critical analysis of the role of the mainstream environmental movement, the media, advertisers, and corporate interests in perpetuating environmental, social, and economic injustices. As he moves the reader forward to action, Novotny reveals himself to be an activist scholar. The final paragraph of the book sums up his message.

The crucial work of the environmental justice movement is to define language itself as the site of political struggle, where individuals can fight to reclaim their own definition of what constitutes the environment and struggle to reconfigure the scientific, legal, and technical definitions of the environment in a more accessible language. Language itself is a site of political struggle, a part of activism no less important than the protest at a chemical facility, an information table at an Earth Day rally, or the demonstrations at a hazardous waste site by communities that for too long have not been part of the postwar environmental movement (2000: 94).

\title{
Shady Practices, Agroforestry and Gender Politics in The Gambia, by Richard A. Schroeder. Berkeley: University of California Press (1999), xxxiv, 172 pp.
}

\section{Reviewed by Barbara P. Thomas-Slayter, International Development Program, Clark University, Worcester, MA}

\begin{abstract}
Richard Schroeder's Shady Practices offers a fascinating and timely analysis of ecology and gendered politics in The Gambia, weaving together an amazing story of men and women caught up in struggles over livelihood strategies, land use, resource tenure and domestic relations and obligations. The cast of characters includes not only the villagers of The Gambia's North Bank community of Kerewan, but also national level agencies and their economic objectives, and international donors with their changing, even contradictory, policies and programs for achieving sustainable development and environments. Schroeder effectively situates this story in the broad context of environment and development theoretical perspectives drawing from the varied frameworks connecting gender, environment and development. He aligns himself most closely with the perspectives of "feminist political ecology" and "feminist environmentalism." These viewpoints focus on the material conditions women face in sustaining viable livelihoods and environments and regard gender, along with class, caste, race, culture and ethnicity, as a critical variable in shaping resource access and control.

Schroeder's story opens in 1986 with his employment by the Gambian field office of the US-based nongovernmental organization, Save the Children Federation. It continues in 1989 and 1991, when he returns to Kerewan with foundation support for dissertation research to carry out a systematic investigation of the emergence of market gardening by women in this Mandinka community and a subsequent introduction of agroforestry practices - with international donor support - which has threatened to undermine the horticultural livelihood strategy. During these periods of field research, his research methods included: a) systematic surveys to obtain basic demographic
\end{abstract}

